\title{
Long-Term Outcome of Cataract Surgery in Eyes with Pseudoexfoliation Syndrome Associated with Weak Zonules: A Case Report
}

\author{
Juris Vanags ${ }^{a, b} \quad$ Guna Laganovska $a^{a, b}$ \\ ${ }^{a}$ Clinic of Ophthalmology, P. Stradins Clinical University Hospital, Riga, Latvia;

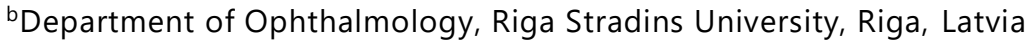

\section{Keywords}

Pseudoexfoliation syndrome · Weak zonules · Late intraocular lens dislocation

\begin{abstract}
A cataract surgery in both eyes was scheduled for an 81-year-old female patient. However, ophthalmic examination revealed marked iridodonesis, phacodonesis and pseudoexfoliative material on the surface of the lens in both eyes indicating weak zonules caused by pseudoexfoliation syndrome, which was more pronounced in the left eye. Cataract surgery was performed initially in the left eye by phacoemulsification. Additionally, iris hooks and capsular tension ring (CTR) were used to stabilize the capsular bag, and the haptic of the intraocular lens (IOL) was sutured to the iris at the end of the surgery. The same procedure except haptic suturing was performed in the right eye after 6 months. The left eye remained stable, whereas the right eye developed considerable anterior capsular contraction 2 months postoperatively. Neodymium-doped yttrium aluminum garnet (Nd:YAG) laser capsulotomy was performed to treat the condition. Moreover, 3 years after the initial surgery, late IOL-CTR-capsular-bag complex dislocation developed in the right eye, and reposition surgery was performed. Three days after IOL-CTR-capsular-bag complex reposition surgery, endophthalmitis developed; the eye responded well to $1 \mathrm{mg}$ intravitreal vancomycin treatment. IOL in the right eye remained stable 3 years postoperatively.




\section{Case Reports in Ophthalmology}

\section{Introduction}

Pseudoexfoliation syndrome is associated with multiple ocular manifestations, including weak zonules [1]. If cataract surgery is necessary in such a case, it might be challenging for surgeons to perform the surgery [2,3]. To improve surgical outcome and long-term prognosis, different devices for weak zonule management have been introduced such as conventional and modified capsular tension rings (CTRs) and iris and capsular hooks [4-6]. Late in-the-bag intraocular lens (IOL) and CTR complex dislocation may develop, despite the use of different devices for weak zonule cases in a period of $\geq 3$ months after cataract surgery [7-10].

\section{Case Report}

Cataract surgery was scheduled for an 81-year-old female patient in January 2013. The best corrected visual acuity (BCVA) was 0.6 (cc $+3.0 \mathrm{Dsph})$ in the right eye and $0.5(\mathrm{cc}+3.0$ Dsph) in the left eye. Intraocular pressure (IOP) was $9 \mathrm{~mm} \mathrm{Hg}$ in the right eye and $8 \mathrm{~mm} \mathrm{Hg}$ in the left eye. Slit lamp examination of both the eyes revealed clear corneas, normal anterior chamber depth, marked iridodonesis and phacodonesis (in the left eye > in the right eye), pseudoexfoliative material on the surface of the lens, and nuclear cataract grade $2 / 3$. The vitreous humor and retina had no significant changes. Cataract surgery in the left eye was initially performed, and a surgical approach including main temporal tunnel incision $(2.75 \mathrm{~mm})$ and nasal paracentesis $(1.2 \mathrm{~mm})$ was performed at the 3 and 9 o'clock positions, respectively. Subsequently, the anterior chamber was filled with viscoelastic material. Following continuous capsulorhexis, additional paracenteses at the 1.30, 4.30, 7.30, and 10.30 o'clock positions were performed, and iris hooks were implanted at the margin of the capsulorhexis to provide lens/capsular bag stability during surgery. A CTR was implanted immediately after introduction of the hooks. Phacoemulsification of the cataractous lens was performed, subcapsular material was removed via manual irrigation-aspiration without additional anterior capsule polishing, and the IOL (Medicontur [877FABY] Medicontur Medical Engineering Ltd., Zsámbék, Hungary) was implanted. Further, the hooks were explanted. Because the IOL-CTR-capsular-bag complex was unstable, IOL haptic-iris fixation was performed using 10/0 polypropylene suture (Fig. 1). Cataract surgery in the right eye was performed on August 2013 using the same technique except IOL haptic-iris suturing. One week after the right eye surgery, the left eye BCVA and right eye BCVA was 0.8 and 0.9 , respectively. Slit lamp examination revealed considerable pseudophakodonesis in the right eye and iris suture and stable IOL with slight decentration in the left eye. Two months after right eye surgery, marked anterior capsule contraction was noted (Fig. 2), and Nd:YAG laser capsulotomy was performed at the anterior fibrotic capsular margin. On February 2016, the patient complained of marked visual acuity decrease in the right eye, and IOL-CTR-capsular-bag complex dislocation was found upon slit lamp examination. Suturing of the CTR edge in the sulcus was performed, using 10/0 polypropylene as fixing suture, allowing the IOL-CTR-capsular-bag complex to be repositioned. IOLCTR-capsular-bag reposition technique consisted of limbal conjunctival incision and creation of scleral flap at the 1 o'clock position and sclerotomy $2 \mathrm{~mm}$ from the limbus under the flap. $1 \mathrm{~mm}$ corneal paracentesis at the 7 o'clock position was performed for insertion of straight needles of polypropylene 10/0 sutures. A 27-G anterior chamber canula was inserted in sclerotomy under scleral flap and the tip of the canula under the CTR edge was positioned; simultaneously, one of the straight needles of polypropylene 10/0 entered the anterior chamber via paracentesis and it was guided to the tip of the $27-\mathrm{G}$ canula through the capsular bag between 
CTR and IOL. After the needle entered the lumen of the canula, both were pulled out through sclerotomy. The same procedure was performed with the second needle, but with the needle passing over the edge of the CTR, thus creating a loop around the edge of the CTR. A knot was created and fixated in the edge of sclerotomy and the IOL-CTR-capsular bag complex was repositioned by tightening the knot. The knot was buried under the scleral flap, while the scleral flap was closed by Nylon 10/0. The conjunctival incision was closed by Vicryl 8/0 single suture, while the paracentesis by simple hydration of the corneal stroma. Perioperative treatment of reposition surgery consisted of neomycin-polymyxin B-dexamethasone (Maxitrol ${ }^{\circledR}$ ) eye drops 4 times per day after surgery. Three days after reposition, endophthalmitis developed in the right eye, but the condition was ameliorated after $1 \mathrm{mg}$ intravitreal vancomycin treatment. No vitreous sample was collected for microbial evaluation. Other treatment for endophthalmitis consisted of topical neomycin-polymyxin B-dexamethasone 8 times per day and cyclopentolate eye drops $1 \%$ twice per day. Additional systemic vancomycin 1,000 mg twice per day was administered intravenously for 5 days. Two months after endophthalmitis, BCVA reached 0.3. On October 2019, BCVA in the right eye was 0.5 (cc-5.0 Dsph), and that in the left eye was 0.6 (cc $+0.75 \mathrm{Dsph}$ ). IOP in the right and left eye was 8 and $11 \mathrm{~mm} \mathrm{Hg}$, respectively. Slit lamp examination showed no pseudophakodonesis and slight IOL decentration in both eyes and posterior capsule opacification in the left eye, but there was no significant effect on visual acuity (Fig. 3). Fundoscopy revealed no significant changes in the optic nerve and retina and more opacity in the vitreous humor of the right eye as a result of history of endophthalmitis.

\section{Discussion}

Cataract surgery in case of weak zonules is more challenging and time consuming and has a higher risk of intraoperative and postoperative complications than ordinary cataract cases $[2,3,8,11]$. Phacoemulsification with capsular stabilizing devices is a more preferred surgical method than extracapsular or intracapsular cataract extraction and pars plana lensectomy combined with vitrectomy $[4,5,11,12]$. If CTR is implanted in case of weak zonules caused by pseudoexfoliation syndrome, most procedures are performed without additional fixation by suturing, and the method shows good visual, positional (IOL well centered), and long-term outcome. Thus, the particular procedure was used as a method of choice in the present case; however, late in-the-bag IOL dislocations have been reported in this group of patients, developing from 2.5 to 8.5 years after the initial surgery $[8,9,13]$. Anterior capsular phimosis as one of possible causes of late IOL dislocation was observed in our case, despite appropriate treatment (Nd:YAG laser capsulotomy) 2 months postoperatively. Late in-the-bag IOL and CTR dislocations were observed 3 years after the right eye surgery. Transscleral repositioning, if possible, of the dislocated IOL-capsular-bag complex is the most preferred method, followed by IOL-capsular-bag complex exchange for other IOL types. Both methods improve visual outcome. IOL exchange surgery shows a higher risk of intraoperative complications and is less cost-effective $[8,10,14]$. Endophthalmitis after IOL reposition surgery is an extremely rare condition. Østern et al. [8] have reported that 1 of 116 eyes develops endophthalmitis after IOL reposition or exchange surgery, but this was not confirmed because of a culturenegative vitreous tap. Subasi et al. [10] have reported that 1 of 39 eyes develops postoperative endophthalmitis after IOL reposition or exchange surgery. Our case might be considered infectious because of the very good response to $1 \mathrm{mg}$ intravitreal vancomycin treatment. If marked zonular weakness or zonular absence of any cause is present, modified CTR ring 
(Cionni) implantation should be considered to provide good IOL-capsular-bag stability and centration $[5,15]$. Our case showed deterioration of zonular support in the left eye during surgery, after removal of capsular bag stabilizers. Iris hook and additional iris fixation was performed to prevent early or late IOL-CTR-capsular-bag complex dislocation.

\section{Conclusions}

Cataract surgery in the presence of weak zonules caused by pseudoexfoliation syndrome is challenging. In cases when zonular support deteriorates during surgery or when there are no other possibilities for IOL-CTR-capsular-bag additional fixation, iris fixation is a good option with good long-term outcome. Eyes with similar status but in which additional fixation was not performed might develop late IOL-CTR-capsular-bag complex dislocation, and the condition requires reposition surgery. Reposition surgery, if IOL-CTR-capsular-bag complex is intact, is not extremely invasive, and visual acuity improves after reposition. However, it might cause severe postoperative complications.

\section{Statements of Ethics}

This case complies with the tenets of the Declaration of Helsinki. The patient provided written informed consent for the publication of this case report.

\section{Disclosure Statement}

The authors have no conflicts of interest to declare.

\section{Funding Sources}

No funding was received or utilized in relation to the preparation of this case report.

\section{Author Contributions}

Juris Vanags: data collection, surgeries, patient follow-up, and manuscript preparation. Guna Laganovska: data and manuscript review.

\section{References}

1 Ritch R, Schlötzer-Schrehardt U. Exfoliation syndrome. Surv Ophthalmol. 2001 Jan-Feb;45(4):265-315.

2 Shingleton BJ, Crandall AS, Ahmed II. Pseudoexfoliation and the cataract surgeon: preoperative, intraoperative, and postoperative issues related to intraocular pressure, cataract, and intraocular lenses. J Cataract Refract Surg. 2009 Jun;35(6):1101-20.

3 Sangal N, Chen TC. Cataract surgery in pseudoexfoliation syndrome. Semin Ophthalmol. 2014 Sep-Nov;29(56):403-8.

4 Gimbel HV, Sun R, Heston JP. Management of zonular dialysis in phacoemulsification and IOL implantation using the capsular tension ring. Ophthalmic Surg Lasers. 1997 Apr;28(4):273-81. 


\section{Case Reports in Ophthalmology}

\begin{tabular}{l|l}
\hline Case Rep Ophthalmol 2020;11:54-59 \\
\hline DOI: 10.1159/000505720 & $\begin{array}{l}\text { @ 2020 The Author(s). Published by S. Karger AG, Basel } \\
\text { www.karger.com/cop }\end{array}$ \\
\hline
\end{tabular}

Vanags and Laganovska: Cataract Surgery in Eyes with Pseudoexfoliation Syndrome Associated with Weak Zonules

5 Cionni RJ, Osher RH. Management of profound zonular dialysis or weakness with a new endocapsular ring designed for scleral fixation. J Cataract Refract Surg. 1998 Oct;24(10):1299-306.

6 Tsai $\mathrm{CH}, \mathrm{Hsiao} \mathrm{CH}, \mathrm{Ku}$ WC. Flexible iris retractors for management of zonular dialysis during planned phacoemulsification. Chang Gung Med J. 2006 Sep-0ct;29(5):499-504.

7 Gimbel HV, Condon GP, Kohnen T, Olson RJ, Halkiadakis I. Late in-the-bag intraocular lens dislocation: incidence, prevention, and management. J Cataract Refract Surg. 2005 Nov;31(11):2193-204.

8 Østern AE, Sandvik GF, Drolsum L. Late in-the-bag intraocular lens dislocation in eyes with pseudoexfoliation syndrome. Acta Ophthalmol. 2014 Mar;92(2):184-91.

9 Koçak Altıntaş AG, Omay AE, Çelik S. Spontaneous Late Intraocular Lens and Capsule Tension Ring Dislocation. Turk J Ophthalmol. 2017 Apr;47(2):106-9.

10 Subasi S, Yuksel N, Karabas VL, Yilmaz Tugan B. Late in-the-bag spontaneous IOL dislocation: risk factors and surgical outcomes. Int J Ophthalmol. 2019 Jun;12(6):954-60.

11 Fontana L, Coassin M, Iovieno A, Moramarco A, Cimino L. Cataract surgery in patients with pseudoexfoliation syndrome: current updates. Clin Ophthalmol. 2017 Jul;11:1377-83.

12 Blecher MH, Kirk MR. Surgical strategies for the management of zonular compromise. Curr Opin Ophthalmol. 2008 Jan;19(1):31-5.

13 Shingleton BJ, Neo YN, Cvintal V, Shaikh AM, Liberman P, O’Donoghue MW. Outcome of phacoemulsification and intraocular lens implantion in eyes with pseudoexfoliation and weak zonules. Acta Ophthalmol. 2017 Mar;95(2):182-7.

14 Kristianslund O, Dalby M, Moe MC, Drolsum L. Cost-effectiveness analysis in a randomized trial of late in-thebag intraocular lens dislocation surgery: repositioning versus exchange. Acta Ophthalmol. 2019 Dec;97(8):771-7.

15 Vasavada AR, Praveen MR, Vasavada VA, Yeh RY, Srivastava S, Koul A, et al. Cionni ring and in-the-bag intraocular lens implantation for subluxated lenses: a prospective case series. Am J Ophthalmol. 2012 Jun;153(6):1144-53.e1.

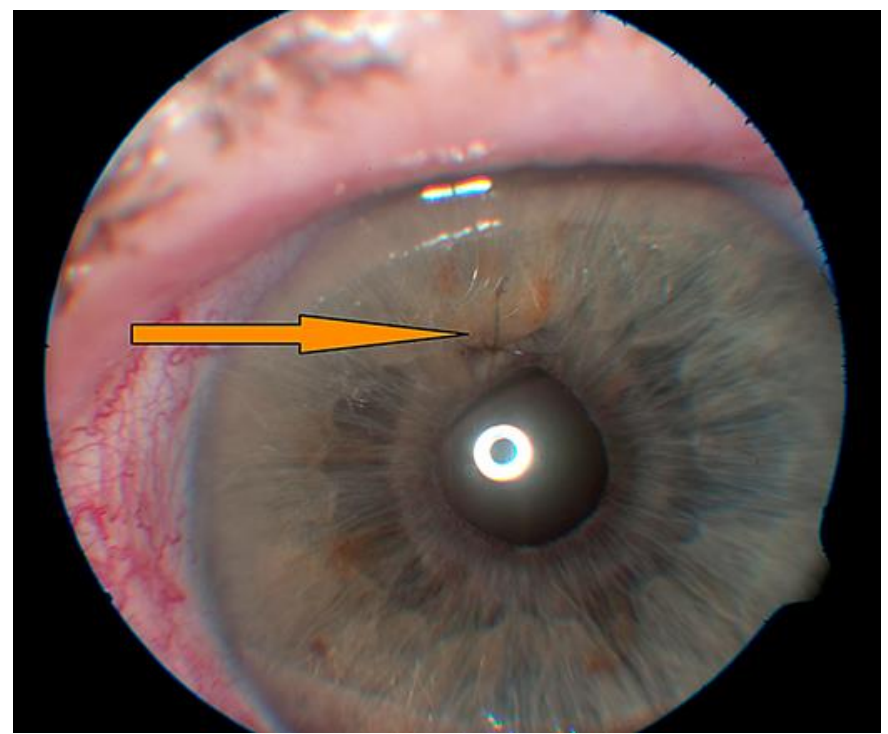

Fig. 1. Left eye 1 month after cataract surgery (February 2013). Iris suture visible at the 12 o'clock position (arrow). 


\section{Case Reports in Ophthalmology}

\begin{tabular}{l|l}
\hline Case Rep Ophthalmol 2020;11:54-59 \\
\hline DOI: 10.1159/000505720 & $\begin{array}{l}\text { C 2020 The Author(s). Published by S. Karger AG, Basel } \\
\text { www.karger.com/cop }\end{array}$ \\
\hline
\end{tabular}

Vanags and Laganovska: Cataract Surgery in Eyes with Pseudoexfoliation Syndrome Associated with Weak Zonules

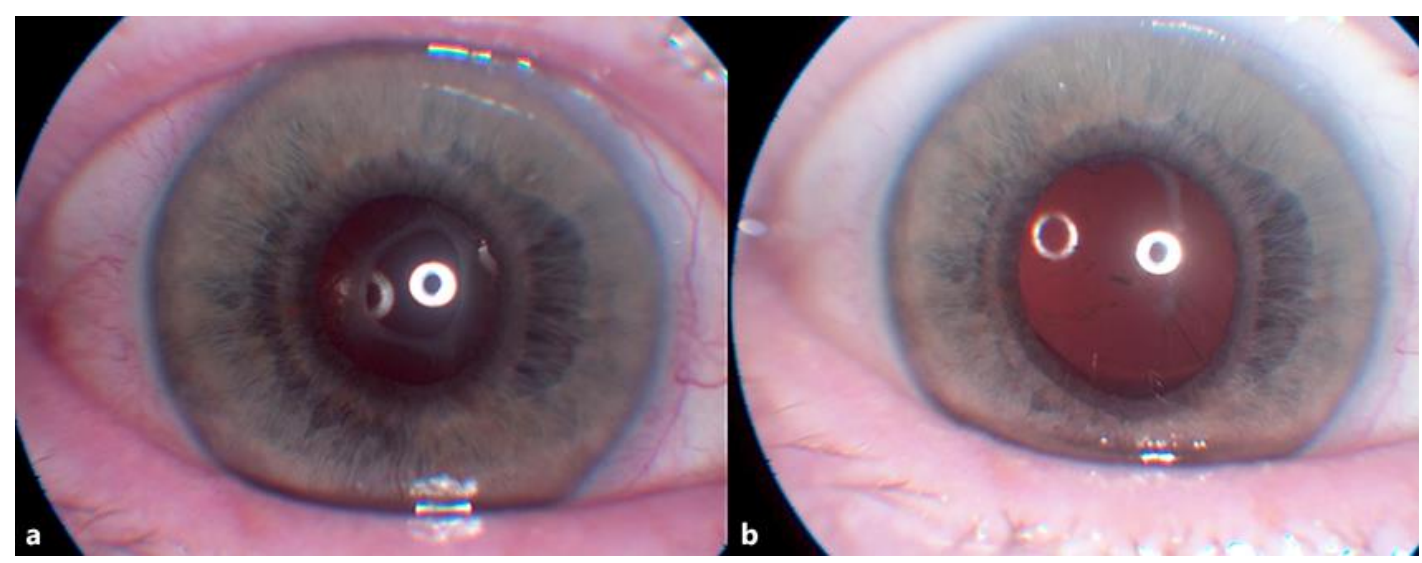

Fig. 2. Right eye 2 months after cataract surgery (October 2013) with anterior capsular opening contraction (a) and after Nd:YAG anterior capsulotomy (b).
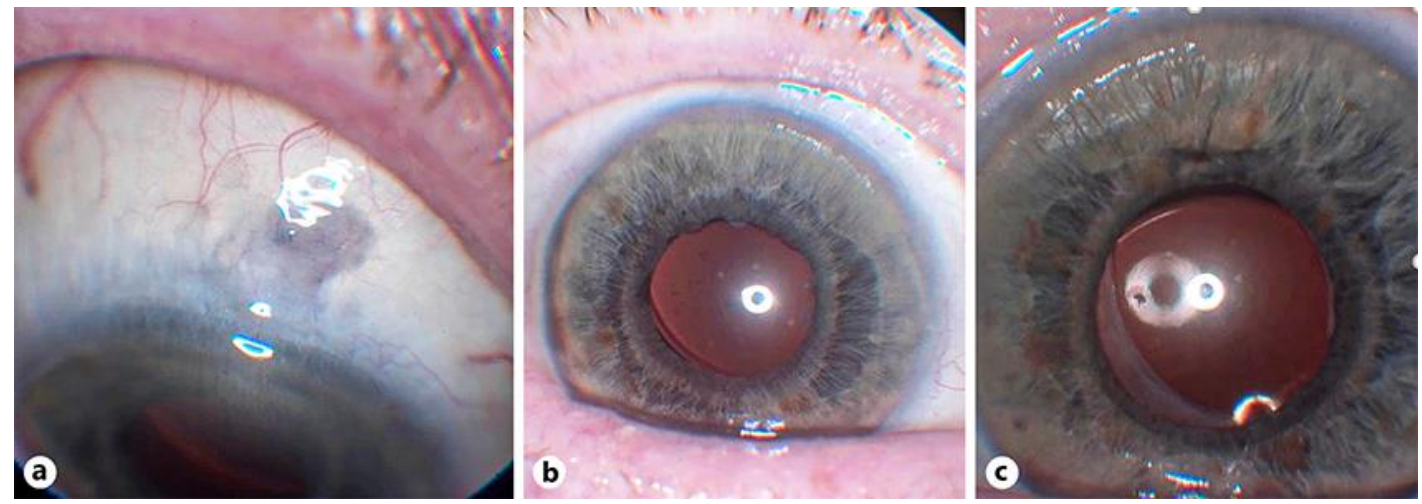

Fig. 3. Current status (October 2019). Transscleral reposition site of the right eye (a). Right eye (b); left eye (c). 